\title{
MEDICO-LEGAL AND OBSTETRIC CHALLENGES OF RECENT DEMOGRAPHIC INCREASES IN MALTA
}

\author{
George Gregory Buttigieg ${ }^{1}$, Kirill Micallef Stafrace ${ }^{1,2}$, Momchil Mavrov ${ }^{3,6}$, \\ Anna Mihaylova ${ }^{4}$, Ekaterina Uchikova ${ }^{5,6}$ \\ ${ }^{1}$ Faculty of Medicine and Surgery, University of Malta \\ ${ }^{2}$ Mater Dei Hospital, Malta \\ ${ }^{3}$ Department of Health Care Management, Faculty of Public Health, \\ Medical University of Plovdiv, Bulgaria \\ ${ }^{4}$ Medical College, Medical University of Plovdiv, Bulgaria \\ ${ }^{5}$ Department of Obstetrics and Gynaecology, Faculty of Medicine, \\ Medical University of Plovdiv, Bulgaria \\ ${ }^{6}$ St. George University Hospital, Plovdiv, Bulgaria
}

\begin{abstract}
The southern Mediterranean island of Malta, strategically located between North Africa and Europe and a full member of the European Union, offers an excellent European standard obstetric service. Yet, this obstetric service, like all other medical disciplines, is undergoing a severe evolutionary challenge imposed by rapid demographic shifts. It also finds itself without significant and relevant medico-legal legislation which is likely to lead to serious acute needs at the interface between the rapidly changing nature and number of foreigners residing in Malta and their medical needs, especially in the obstetric sector.

The article looks at several factors, which argue for the immediate need of implementation of such legislation. One aspect of crucial importance is the demographic fact of rapidly changing profile of the patients making use of the Maltese Obstetric Service (MOS). This is the result of an influx of both EU nationals as well as irregular migrants, mostly of sub-Saharan origin. Both provide their own form of challenges to the MOS. In both, albeit more likely in the case of EU nationals, these challenges may easily find expression and resolution in eventual medico-legal action.
\end{abstract}

Keywords: medico-legal legislation, obstetric service, Malta, immigrants, demographic changes

Address for correspondence:

Anna Mihaylova

Medical College

Medical University of Plovdiv

120 Bratya Buxton St

4004 Plovdiv

e-mail:anna.mihaylova@mu-plovdiv.bg

Received: May 4, 2019

Accepted: June 21, 2019

\section{INTRODUCTION}

\section{Lack of Medico-Legal Awareness}

Obstetrics is one of the most likely medical disciplines to be associated with court litigation. In a 1991-2005 US study covering 40,916 physicians and 233,738 physician-years (1), OBGYN ranked the seventh out of 26 in a list looking at the proportion of physicians facing malpractice claims according to 
speciality. The actual incidence varies from country to country and in the USA from state to state, but there is no doubting the confrontational popularity of OBGYN. The European scenario phenomenon leaves no room for complacency. France, Germany, Italy, Portugal are a few of the EU countries which have statistically confirmed the expected rise. In spite of this, there is both a great scarcity of published studies on the topic (2) as well as a frightening underestimation of the consequences of court action in professionals' daily clinical practice (3). This sense of a fool's paradise also exists in the southern Mediterranean island of Malta. This is evidenced by features, which starkly stand out in the face of European level. No official (or otherwise) litigation statistics exist while there is an evident lack of appropriate medical malpractice law (4). Medical indemnity insurance only became a legal requirement by the Medical Council, as enforced by subsidiary legislation, on 14 March 2014. Yet, as far back as 2004, the president of the Medical Association of Malta already described the sharp increase in court cases as being the tip of the iceberg (5).

\section{An Efficient Service}

It is crucial to stress that in spite of the laissezfaire attitude of the Maltese Obstetric Service (MOS), such a spirit does not at all pervade the actual service, which is an excellent one. The following official data are supplied by the National Obstetric Information System (NOIS), which is an internationally recognised body for monitoring and publishing all Maltese obstetric activities. It was originally launched in collaboration with the WHO - OBSQID project at the beginning of 1999 (6).

Referring to the NOIS 2016 report, we find that in the Maltese Islands, there were

4465 total births with 0 maternal deaths.

For fetal weights of $500 \mathrm{~g}$ and over:

$\diamond$ A fetal mortality rate of 3.7/1,000 total births was registered;

$\diamond$ A neonatal mortality of 4.9/1,000 live births;

$\diamond$ An early neonatal mortality of 3.7/1,000 live births;

$\diamond$ A late neonatal mortality of 1.1/1,000 live births, and

$\diamond$ A perinatal mortality rate of $7.5 / 1,000$ total births.
One must also hasten to add that termination of pregnancy is illegal and fetal deaths from serious anomalies are therefore included in the statistics.

\section{AIM}

The purpose of this article is to review the factors that affect medical care and in particular obstetric care in the Maltese population, to discuss the challenge of migrant demographic growth, and to define the need for the introduction of medico-legal standards.

\section{MATERIALS AND METHODS}

A literature review of medical legal literature published in world scientific databases has been made. The data has been analysed and interpreted by the author team, along with exposed own personal experience on the topic.

\section{EXPOSITION}

\section{A Changing Scenario}

The MOS is experiencing major challenges resulting from an acute increase in both the quantity as well las the ethnic origin of patients. The implications extend far beyond the superficial, comprising religious, sociocultural and language elements, none of which may be underestimated.

There have been two major sources of patient influx, namely European and the sub-Saharan, in the majority with other irregular immigrants. While both groups increase the pressure effect of increased demand, the irregular immigrant (I.I.) group presents more of a socio-religio-cultural challenge while the European immigrant (E.I.) group exacts demands from which one may not exclude potential risks of litigation problems. However, neither can one exclude the possibility that the immigrant group will not pose a similar threat, because much guidance is available to them - and rightly so - from groups such as Médecins Sans Frontières. However, the two groups ascribe to different priorities of religio-sociocultural and psychological needs, which may translate into different potential medico-legal confrontation scenarios.

Since joining the European Union on May 2004, Malta has seen numerous citizens from fellow European member states settling in Malta, both temporarily as well as permanently. There are sever- 
George Gregory Buttigieg, Kirill Micallef Stafrace, Momchil Mavrov et al.

al factors attracting Europeans to the smallest member state of the EU, such as climate, a safe environment, an ideal place where to raise a family, and a low crime rate.

Irregular immigration has also added its fair share of foreign input. It is estimated that 17,743 , mostly African, migrants have arrived in Malta in a decade or less (7). In 2017 the top asylum applications to Malta were from Syria, Libya, Somalia, Eritrea, Iraq and a substantial section which cannot be classified. Relative to its size and resident population, Malta, with 30 immigrants per 10,000 persons, had the second highest immigration rate, second only to Luxembourg with 42 immigrants per 10,000 persons (8). Both the E.I. and the I.I. groups contributed to the $19.9 \%$ (almost a $1 / 5^{\text {th }}$ ) increase of baby deliveries to non-Maltese women. The state of demographic flux can be traced in Table 1, where from a low $4.9 \%$ in 2000 , the non-Maltese deliveries rose to $19.9 \%$ in 2016.

Of Culture, Communication and the Changing Population Profile
Many factors are involved at the interface of the changing population structure and MOS. One such, and not to be underrated, deals with cultural differences and communication. There are also background differences in the obstetric care offered in the country of origin. Thus, the European population likely originates from EU countries, which, among other things, offer pre-natal screening for fetal anomalies with a view to offering termination of pregnancy. Neither one nor the other are offered in Malta, where termination of pregnancy is a criminal offence. It is possibly a question of time before one such non-Maltese attending the MOS services will bring an unlawful birth type of claim at the European Court of Human Rights for being deprived of the right to abort a child suffering from some anomaly or other. Other types of screening offered in other EU countries, e.g. toxoplasmosis screening in France, is not offered in Malta (nor in some other countries) and this organizational arrangement is often not received well by the individual patient.

On the other hand, a sub-Saharan couple who is, generally speaking, expecting less from the ser-

Table 1. Deliveries by reported nationality of mother for all deliveries on the Maltese Islands

\begin{tabular}{lc|c|c|c|c|c|}
\hline \multirow{2}{*}{ Nationality / } & \multicolumn{2}{c}{ Maltese } & \multicolumn{2}{c}{ Non-Maltese } & \multicolumn{2}{c}{ Unknown } \\
\cline { 2 - 6 } Year & Number & $\%$ & Number & $\%$ & Number & $\%$ \\
$\mathbf{2 0 0 0}$ & 4096 & 95.0 & 211 & 4.9 & 4 & 0.1 \\
$\mathbf{2 0 0 1}$ & 3737 & 95.4 & 178 & 4.5 & 3 & 0.1 \\
$\mathbf{2 0 0 2}$ & 3662 & 94.6 & 170 & 4.4 & 41 & 1.1 \\
$\mathbf{2 0 0 3}$ & 3687 & 92.3 & 220 & 5.5 & 88 & 2.2 \\
$\mathbf{2 0 0 4}$ & 3558 & 92.7 & 168 & 4.4 & 112 & 2.9 \\
$\mathbf{2 0 0 5}$ & 3512 & 92.3 & 237 & 6.2 & 55 & 1.4 \\
$\mathbf{2 0 0 6}$ & 3491 & 91.3 & 288 & 7.5 & 43 & 1.1 \\
$\mathbf{2 0 0 7}$ & 3511 & 91.1 & 308 & 8.0 & 34 & 0.9 \\
$\mathbf{2 0 0 8}$ & 3729 & 89.8 & 402 & 9.7 & 23 & 0.6 \\
$\mathbf{2 0 0 9}$ & 3711 & 90.2 & 376 & 9.1 & 25 & 0.6 \\
$\mathbf{2 0 1 0}$ & 3581 & 90.6 & 365 & 9.2 & 6 & 0.2 \\
$\mathbf{2 0 1 1}$ & 3740 & 88.5 & 479 & 11.3 & 7 & 0.2 \\
$\mathbf{2 0 1 2}$ & 3668 & 87.9 & 501 & 12.0 & 6 & 0.1 \\
$\mathbf{2 0 1 3}$ & 3501 & 86.0 & 564 & 13.8 & 8 & 0.2 \\
$\mathbf{2 0 1 4}$ & 3533 & 82.6 & 733 & 17.1 & 9 & 0.2 \\
$\mathbf{2 0 1 5}$ & 3544 & 80.8 & 838 & 19.1 & 3 & 0.1 \\
$\mathbf{2 0 1 6}$ & 3565 & 80.0 & 889 & 19.9 & 1 & 0.1 \\
\hline
\end{tabular}


vice finds exception to other aspect of the service. Thus, being seen by a male doctor, discussing personal questions on sexuality may offend the patient or her husband, and accepting a Caesarean section for impending fetal damage or death may not be acceptable to the patient.

Modern ethical concepts of patient autonomy give the patient every right to refuse such options. However, to date, the Maltese approach has been to apply to the Attorney General for sanctioning of such a C-section (9). If challenged at European level, such procedures are hardly likely to win the day.

Language, attitude, xenophobia, religion, social and cultural facets may all play major roles in in effective or broken down communication attempts. Without adequate communication, a host of crucial steps in the process of healing - in any discipline are crippled. One may not obtain a good medical history, nor offer valid disclosure with a view to obtaining consent, nor secure empathy or bonding, give instructions, e.g. during birth, neither can one give important discharge instructions and information. Furthermore, good communication and bonding are also crucial in minimising the chance of malpractice suits (10). Such communication failure may be due to failure of or wrong interpretation, but the presence of an interpreter may not necessarily solve all the issues and sometimes may complicate them, especially if he/she is from the same tribe or is a male.

In a small island, such as Malta, with a traditionally relatively close-knit (generally speaking) community, doctor-patient communication is more often than not, excellent. The sudden introduction of multiple challenges to communication should not be underestimated for such communication is also an extremely important factor in potentially limiting medical complaints from treatment and solving them before the litigation attains court status. This, of course, is a general statement, and there has been increasing evidence of an alarming increase in court litigations even about minor cases (5). Communication and bonding are crucial in minimising the chance of malpractice suits (9). The introduction of a foreign group of patients, especially in large numbers and in a short time, may add difficulty in such communication and bonding.
Some Aspects of the Challenge Posed by Irregular Immigrants

The sub-Saharan and other irregular migrants pose a greater challenge to communication than the European counterpart. Here, absent or diminished patient communication is often the order of the day. Other factors compound the situation. The very presence of a male obstetrician may make a patient clam up about personal details. This may lead to serious loss of critical information on history taking such as a previous abdominal delivery and cardiac or respiratory problems. Even the age and the parity are, at times, wrongly conveyed. These problems of language and sociocultural origin are often part of a greater religious-social complex, which for one thing fosters umbrage at a male wanting to know about "women things" (9). It must be remembered that in some cases we speak of a patient who may have been living in the desert but a few months previously. The culture shock and resulting mental withdrawal is often underestimated or never appreciated at all.

Malta is far from being the first country to experience such obstetric and potential medico-legal problems resulting from communication problems. As in many European countries, access to care is decreased for undocumented migrants in the Netherlands due to legislation. Thus, these groups face similar problems, that is, the initial lack of knowledge on the Dutch health care system, language problems, and difficulties arising in the communication with health care providers who have a different cultural background than the patient (11).

Referring to the USA experience of the problem in its broad equivalence, Johnson et al. write about the potential lack of care resulting from such lack of communication: objective differences in the quality of physician-patient communication among African American and Caucasian patients that mirror previously documented differences in the patients' perceptions of their quality of health care (12).

It behoves the Maltese obstetrician, practising at this specific interface point of cross-cultural encounter, to keep well in mind the firm existence of empiric evidence for a direct, causal effect of the doctor-patient relationship on medical patients treatment perceptions and malpractice claim intentions in the event of an adverse medical outcome (13). 
And he must also remember that care in these circumstances may prove challenging, even in simple things like the (un)timely initial booking for antenatal care. Disparate conformity with the requested rules of care of MOS, irrespective of social, economic, religious or cultural reasons, may ultimately reflect in the overall health status of the communities in which women and their families live (14). It is the obstetrician who must face the end result of increasing fetal or maternal morbidity and mortality.

The irregular migrant, often comes from a generally degrading and terrifying background and very limited, if any, obstetric care. A sub-Saharan woman in Africa has a 1 in 16 chance of dying in pregnancy/childbirth compared to 1 in 4,000 in a developed country (15). In Malta the only study, which has looked at the situation, has shown that women from the sub-Saharan and Maghreb region were both statistically less likely to have a planned delivery than the overall population, more likely to deliver by spontaneous vaginal delivery and had a higher proportion of infants under $2500 \mathrm{~g}$ (16). Such a patient is inured to suffering, hardship, abuse, as well as to high maternal and perinatal mortality. Co-operation with Western science and culture, including organised maternity care, will seem alien and probably, at least initially, pointless and at times even suspicious. But eventually, with time, comes discernment and co-operation. Eventually, even potential medicolegal confrontation may come, which is a sacrosanct right. Even if never granted immigration status, such a patient will always - thankfully - find a voice at the Court of Human Rights.

In this regard, it is noted that the Strasbourg Court has repeatedly considered cases involving violations of one of the subjective health rights of nationals of States Parties to the European Convention for the Protection of Human Rights and Fundamental Freedoms (ECHRFF) (17), such as Malta. It is characteristic that the ECHRFF has no explicit provision governing the right to health or other health rights and therefore applicants base their complaints on one of the following rules of law: Article 2 (right to life), Article 3 (prohibition of torture and of inhuman treatment), Article 5 (right to liberty and security of person), Article 8 (right to respect for private and family life), and Article 14 (prohibition of discrimination) of the Convention. These provisions are directly or indirectly connected with the subjective health rights of nationals and ensure their protection. For example, in the cases of Glass vs. The United Kingdom, V. C. vs. Slovakia and N. B. vs. Slovakia (18), the Strasbourg Court states that there has been a violation of Article 8 of the Convention, for failure to comply with patient's right to informed consent in the first case, and for violation of Article 3 of the Convention in the follow-up cases, because of sterilizations performed on the applicants, which grossly interfered with their physical integrity. In Aslya Aden Ahmed vs. Malta (19) the European Court of Human Rights, under violation of Articles 3, 5-1, and 5-4, fined Malta 30,000 euros ( $£ 26,000 ; \$ 40,000$ ), plus 3,000 euros in costs, for action which led to a miscarriage. Even if malpractice as such were not the issue here, it is disconcerting to hear ECHR quoting a complete lack of access to open air and exercise for periods of up to three months, an inadequate diet, and the particular vulnerability in a woman carrying an unborn child. It may well be a matter of time before the subject matter of such court action would be obstetric malpractice, whatever the initial mechanism contributing to the end result.

MOS is expected to maintain its excellent standards, no matter how great the challenges. And this firstly, out of its duty to the individual and secondly, because where it fails, a legal response may be close by.

Some Anomalies of the Present Maltese Medico-Legal Legislation

In Malta, there exists the misconception, probably correct until about twenty years ago, that suing of the medical profession, including for obstetric liability, is a rather rare occurrence. It would be unwise to rest on this assumption, especially in the present complex and multi-factorial shifting paradigm of patient care. Even as far back as 2013, the President of the Maltese Medical Association referred to Malta's legal system, vis-a-vis medical malpractice, as archaic, and furthermore added that the sharp increase in cases is merely the tip of the iceberg (5). The persistent general laissez-fare attitude is partly the result of the fact that the malpractice crisis has not yet breached our shores (4). Hence, no obstetric or indeed medical landmark cases have inculcated the need to legally establish practice changes. 
The local legal system is so archaic that Maltese law deals with the court cases of alleged negligence, not as a specific wrong, but rather, under the general category of the law of Tort, which is an instrument for providing remedies for civil negligence in general (20). Furthermore, and this is peculiar to Malta, on perusing the limited case law reveals the interesting feature that where a medical professional is concerned, gross negligence must be proven and not simple negligence or culpa (21) - a situation which is rather protective of the medical practitioner in regard to civil liability (21).

Although this paper cannot possibly delve into a complete analysis of the failings of the current medical law, one may illustrate specific lacunae by reference to a crucial absence of one aspect, namely the fact that there is no Maltese case law dealing with non-disclosure of information. Hardly the ideal set-up for justice to prevail, especially in the importance afforded to patient autonomy generally in $\mathrm{Eu}-$ rope in 2019.

\section{SUMMARY}

\section{The Quietly Approaching Challenge}

Even without the clear signs of the massive demographic flux of patients using MOS, there has been an urgent and persistent call for the Maltese legal system to shore up its medico-legal confrontation scene. Adding to this ever-increasing need is the demographic influx from Europe and the sub-Saharan region, with the former's likely challenges being more immediate than the latter's.

Even basic argumentation of the medico-legal status quo in Malta and in places like UK would make clear the gross lack of equivalence, never mind harmonisation. And yet both countries are members of the EU. Take informed consent, which in the UK, among other countries, has witnessed the latest and most universal emphasis (22). The concept of a patient's informed consent developed in the late 1960s and early 1970s in the practice of US courts. In a number of cases, US jurisdictions support the idea that prior to any medical intervention, physicians should seek to obtain patient's informed consent, which leads to the recognition of the right to informed consent as an integral part of medical practice and a fundamental right of every patient (23). One of the earliest cases involving medical treatment without the patient's consent were the cases of Mohr vs. Williams, Pratt vs. Davis, Salgo vs. Stanford University, Schloendorff vs. Society of New York Hospitals, and others (24). The principle of informed consent is to protect the patient's wellbeing and integrity, and to promote his or her autonomy as a legal entity (23). In most European countries and in the United States, the legal institute of informed consent is associated with statutory obligation of physicians to disclose certain information to patients regarding diagnosis and treatment, possible risks and benefits of it, and alternatives to the chosen treatment. Each physician is obliged to fulfill this duty and only after the patient receives the necessary information, the latter has the right to express his or her informed consent, respectively, to refuse treatment. In the Bulgarian legal doctrine, informed consent is defined as a process in which a health care provider consistently informs the patient and subsequently obtains the patient's consent for a particular clinical action to be undertaken (25).

In Malta discussing consent and eliciting the universal response of pre-operative consent in most minds is limited to the signing of a form, rather than to a process revolving around an informed discussion and being symbolised by the signing (or not) of the consent form. And obstetricians are hardly to blame for this attitude, like that of doctors from all disciplines, because the wake-up call has not been sounded yet. Or, rather, no one has heard it - yet.

And if consent in general has not yet gained its fair share of importance, its constituting elements have fared even worse. The concept of being held liable for not disclosing what $\mathrm{u}$ should be disclosed may have ruined many obstetricians' lives in the UK or the USA. In Malta, obstetricians may not have any idea of its real importance until a case for wrongful birth is brought at the European Court by a patient complaining that her fetal anomaly was neither diagnosed nor was the information disclosed to her along with advice of what may be done. Some element of protection exists from the constitution, which states that termination of pregnancy is a criminal act. But, as for the actual diagnosis, one may reason that knowing about a fetal anomaly may be important for a family to prepare itself for the misfortune and not necessarily to destroy the malformed child. As matters stand now, although a fetal anomaly ultrasound 
George Gregory Buttigieg, Kirill Micallef Stafrace, Momchil Mavrov et al.

scan is routinely carried out at $18-20$ weeks, no antenatal biochemical or other tests are offered by MOS. It is not beyond reasonable imagination that a patient with undiagnosed fetal anomalies will sooner or later raise a medico-legal issue in the local courts as well as the European Court of Human Rights.

Here is another peculiar feature in the Maltese legal system, which contributes to the present anomalous state of affairs. This is the fact that for a medical practitioner (and here we are not limited to OBGYN, but all medical disciplines) the seemingly traditional "protection from civil suing unless for a gross matter" pales into existence by the frequency of legal action at both civil and criminal levels, when action is taken. There is no adequate "filter mechanism" in the current law to eliminate the extremely high incidence of criminal action taken against doctors in serious cases of alleged medical negligence in Malta relative to countries like the UK and the USA. And essentially all of these cases are ruled by the court in favour of the doctor - this itself speaks volumes against this archaic aspect of the law.

There is no need for Malta to re-invent the wheel. Both the UK and the USA (5), have established relevant legislation, which, through case law studies, has been honed to great functionality. These can easily serve as a beacon to the Malta. Once established, this aspect of medical law, will contribute to justice of patient and doctor as well as induce an even higher quality of practice, both ethically and scientifically. It will also put MOS on better footing to deal with litigation arising out of the new immigratory aspect hitting the MOS. Time will teach and refine, but basic medico-legal changes are long, long overdue.

\section{REFERENCES}

1. Jena A, Seabury S, Lakdawalla D, Chandra A. Malpractice risk according to physician specialty. N Engl J Med. 2011; 365(7):629-36. doi: 10.1056/ NEJMsa1012370.

2. Domingues AP, Moura P, Vieira DN. Lessons from a decade of technical-scientific opinions in obstetrical litigation. J Forensic Leg Med. 2014;25:91-4. doi: 10.1016/j.jflm.2014.04.012.

3. Hammond CB. The decline of the profession of medicine. Obstet Gynaecol. 2002;100(2):221-5. doi: 10.1016/s0029-7844(02)02144-0.
4. Bernard R. Medical malpractice - the need for local legislation. Faculty of Laws, University of Malta, LL.D. Thesis; 2008.

5. Dr. Stephen Fava (2013) speaking at the Medicolegal seminar organised by the Medical Association of Malta 15/10/04. Available at: http://www.mam. org.mt/newsdetail.asp?i=352\&c=1.

6. Department of Health Information. Available at: https://deputyprimeminister.gov.mt//en/dhir/ documents/hnbs_and_annual_report.pdf.

7. The Telegraph 2 March (2018).

8. Eurostat Migration and migrant population statistics. Available at: http://ec.europa.eu/ eurostat/statistics-explained/index.php/ Migration_and_migrant_population_statistics.

9. Buttigieg GG. (2017) Obstetric and Medico-Legal Challenges Posed by Sudden Immigrant Shift in a Southern Mediterranean Island. Anthropol. 2017; 5:185, doi:10.4172/2332-0915.1000185

10. Khan MS. (2008-2012) [Internet] Medical Malpractice - Lack of Communication is the Biggest Cause;- [cited 2013 Jul 10]. Available from: http://www.freearticleforyou.com/Health-andFitness/Healthand-Fitness/medical-malpracticelack-of-communication-isthe-biggest-cause.html.

11. Dorn T, Ceelen M, Tang MJ, Browne JL, de Keijzer KJC, Buster MCA, et al. Health care seeking among detained undocumented migrants: a crosssectional study. BMC Public Health. 2011; 11:190. doi:10.1186/14712458-11-190.

12. Johnson RL, Roter D, Powe PHR, Cooper LA. Patient race/ethnicity and quality of patientphysician communication during medical visits. Am J Public Health. 2004; 94(12):2084-90. doi: 10.2105/ajph.94.12.2084.

13. Moore PJ, Adler NE, Robertson PA. Medical malpractice: the effect of doctor-patient relations on medical patient perceptions and malpractice intentions. West J Med. 2000; 173(4):244-50. doi: 10.1136/ewjm.173.4.244.

14. Bryant AS, Worjoloh A, Caughey AB, Washinghton AE. Racial/ethnic disparities in obstetrical outcomes and care: prevalence and determinants. Am J Obstet Gynecol. 2010;202(4):335-43. doi: 10.1016/j.ajog.2009.10.864.

15. Unicef. Millenium development goals. Available at: http://www.unicef.org/mdg/maternal.html. 
16. Savona-Ventura C, Buttigieg GG, Gatt M. Obstetric outcomes in immigrants of African nationality. Int J Risk Safety Med. 2009; 21:147-52.

17. Council of Europe, European Convention for the Protection of Human Rights and Fundamental Freedoms, as amended by Protocols Nos. 11 and 14, 4 November 1950, ETS 5. Available at: https://www. refworld.org/docid/3ae6b3b04.html [accessed 27 January 2020].

18. ECHR (2004) Judgement 09.03.2004 [Section IV]. Glass v. The United Kingdom, application no. 61827/00. ECHR (2011) Judgement 08.11.2011 [Section IV]. V. C. v. Slovakia, application no. 18968/07; ECHR (2012) Judgement 12.06.2012 [Section IV]. N. B. v. Slovakia, application no. 29518/10.

19. ECHR 231 (2013) 23.07.2013. Application No. $55352 / 12$.

20. Grima K. The civil consequences of negligence in the medical profession. Unpublished LLD thesis; 1999.
21. Pound R, DeRosa ML. The Aquilian culpa, in which the fault does not extend to intentional aggression. An Introduction to the Philosophy of Law (book); 2017. ISBN 9781560009405

22. Buttigieg GG, Micallef Stafrace K. Medico-legal medicine: family practice and the latest views on disclosure of information and consent. Int J Fam Commun Med. 2018;2(2):92-5.

23. Mavrov M. The law institute of patient's informed consent. Publishing house Stovi Group Bulgaria; 2018. p. 19-24.

24. Mohr v. Williams, 95 Minn. 261, 104 N.W. 12, 1905 Minn. LEXIS 667 (Minn. 1905); Pratt v. Davi, 224 IL. 300, 79 N.E. 562 (1906); Salgo v. Leland Standford Jr. Univ. Bd. of Trustees. 154 Cal. App. 2d 560, 317 P.2d 170 (1957); Schloendorff vs. Society of New York Hospital. 211 N.Y. 125, 105 N.E. 92 (1914), (Full text via HathiTrust Digital Library).

25. Zinovieva D, Salchev P. Patient's rights. Sofia: Ciela; 1998. 